\title{
REVIEW
}

\section{Lymphatics in lymphangioleiomyomatosis and idiopathic pulmonary fibrosis}

\author{
Connie G. Glasgow*, Souheil El-Chemaly\# and Joel Moss*
}

ABSTRACT: The primary function of the lymphatic system is absorbing and transporting macromolecules and immune cells to the general circulation, thereby regulating fluid, nutrient absorption and immune cell trafficking. Lymphangiogenesis plays an important role in tissue inflammation and tumour cell dissemination. Lymphatic involvement is seen in lymphangioleiomyomatosis (LAM) and idiopathic pulmonary fibrosis (IPF).

LAM, a disease primarily affecting females, involves the lung (cystic destruction), kidney (angiomyolipoma) and axial lymphatics (adenopathy and lymphangioleiomyoma). LAM occurs sporadically or in association with tuberous sclerosis complex (TSC). Cystic lung destruction results from proliferation of LAM cells, which are abnormal smooth muscle-like cells with mutations in the TSC1 or TSC2 gene. Lymphatic abnormalities arise from infiltration of LAM cells into the lymphatic wall, leading to damage or obstruction of lymphatic vessels. Benign appearing LAM cells possess metastatic properties and are found in the blood and other body fluids.

IPF is a progressive lung disease resulting from fibroblast proliferation and collagen deposition. Lymphangiogenesis is associated with pulmonary destruction and disease severity. A macrophage subset isolated from IPF bronchoalveolar lavage fluid (BALF) express lymphatic endothelial cell markers in vitro, in contrast to the same macrophage subset from normal BALF. Herein, we review lymphatic involvement in LAM and IPF.

KEYWORDS: Chylous effusions, lymphangiogenesis, lymphangioleiomyoma, metastasis, tuberous sclerosis complex, vascular endothelial growth factors

\section{LYMPHANGIOLEIOMYOMATOSIS}

Lymphangioleiomyomatosis (LAM) is a multisystem disease involving lung (cystic destruction), kidney (angiomyolipomas (AMLs)) and axial lymphatics (adenopathy and lymphangioleiomyoma) [1-6]. LAM occurs in a sporadic form and in association with tuberous sclerosis complex (TSC), an autosomal dominant disorder of variable penetrance characterised by seizures, mental retardation, autism and tumours of the brain, kidney, heart, retina and skin, which results from mutations in the TSC1 or TSC2 genes [7] LAM is caused by the proliferation of abnormal smooth muscle-like LAM cells, which have TSC1 or TSC2 mutations [8]. Sporadic LAM is relatively uncommon, primarily affecting females of childbearing age [1-6] at an estimated frequency of 2.6

per 1 million cases per year in the population at risk (females aged 20-69 yrs) [3]. Cystic lung lesions may lead to progressive impairment of pulmonary function, resulting in respiratory failure, oxygen dependency or lung transplantation [8]. Dyspnoea and spontaneous pneumothorax are common symptoms of patients with LAM [1-6]. Due, in part, to the similarity in symptoms of patients with LAM to those seen in other more widespread diseases, an average of 5 to 6 yrs delay is seen between onset of symptoms and definitive diagnosis [9]. 10-yr survival is generally thought to be $79-91 \%[3,10]$.

Lymphatic abnormalities seen in patients with LAM include lymphadenopathy, lymphangioleiomyomas and chylous effusions (chylous ascites

For editorial comments see page 171.

Some of the results of this article have been previously presented at the 4th International meeting on Pulmonary Rare Diseases and Orphan Drugs, Milan, Italy, February 25-26, 2011.

\section{AFFILIATIONS}

${ }^{*}$ Cardiovascular and Pulmonary Branch, National Heart, Lung, and Blood Institute, National Institutes of Health, Bethesda, MD, and

\#Division of Pulmonary and Critical Care Medicine, Brigham and Women's Hospital, Harvard Medical School, Boston, MA, USA.

CORRESPONDENCE

J. Moss

Cardiovascular and Pulmonary

Branch, NHLBI

National Institutes of Health

Bldg.10/Room 6D05/MSC-1590

Bethesda

MD 20892-1590

USA

E-mail: mossj@nhlbi.nih.gov

Received:

Dec 202011

Accepted after revision:

Jan 062012

PROVENANCE

Submitted article, peer reviewed 
and chylothorax) $[1,11]$. Lesions are primarily located in the retroperitoneum and mediastinal regions [2, 12]. Lymphadenopathy is the most prevalent lymphatic manifestation in LAM $[2,3,11]$, with some lymph nodes as large as $4 \mathrm{~cm}$ in diameter [11]. The incidence of lymphangioleiomyoma, chyle-filled tumour-like lesions that appear to result from obstruction in lymphatic vessels by infiltration of LAM cells in the lymphatic wall, in LAM patients is $29 \%$ [13].

Lymphangioleiomyomas appear on computed tomography (CT) scans as well-circumscribed lobulated masses filled with chylous material [11, 12, 14, 15]. Lymphatic masses in LAM result from the proliferation of LAM cells within lymphatic channels, lymph nodes or the thoracic duct. The subsequent dilatation and obstruction can result in cystic collections of chylous material. Overdistension of these structures may cause them to rupture leading to the development of chylothorax or chylous ascites [11, 14-16]. LAM cells found in these lesions may infiltrate the surrounding soft tissues [12, 14]. AvILA and co-workers $[17,18]$ observed diurnal variation in the size of lymphangioleiomyomas in patients with LAM due, in part, to changes in lymph flow caused by food intake during the day. Lymphangioleiomyomas may become sufficiently large to cause partial displacement of abdominal structures [11] and chylous material has been observed to enter the pleural cavities apparently by rupture of the pleura or by transudation [14]. These data demonstrate that lymphatic involvement may be responsible for symptoms in LAM.

In LAM, high-resolution CT (HRCT) scans of the chest reveal thin-walled cystic lesions dispersed homogeneously throughout the lung parenchyma [1, 2]. Hyperplastic type II pneumocytes line the surfaces of cysts and react with antibodies to proliferating cell nuclear antigen (PCNA) $[19,20]$. LAM cells form clusters or nodules of cells that are located at the border of the cysts and along pulmonary blood vessels, lymphatics and bronchioles [20]. Cysts result from the proliferation and secreted products of LAM cells, such as matrix metalloproteinases (MMPs), leading to destruction of lung parenchyma [20].

LAM cells in the lung nodules are grouped into two cell types by morphologic and mitotic characterisation. Small spindleshaped cells most often react to PCNA [21] and appear to be more proliferative; the larger epithelioid cells are more likely to react with HMB-45 (a monoclonal antibody that reacts with the premelanosomal protein gp100) [20, 21], consistent with a more differentiated state [22]. Slit-like channels, lined with lymphatic endothelial cells, traverse LAM foci or nodules in lung and extrapulmonary LAM-affected organs (i.e. lymph node, uterus and ovaries) $[23,24]$ and appear to be lymphatic capillaries.

The CT lung scans of $\sim 30-40 \%$ of female patients with TSC show lung cysts similar to those observed on CT scans of patients with sporadic LAM [25-27]. The TSC1 or TSC2 tumour suppressor genes are responsible for LAM [28]. TSC1, located on chromosome 9 (9q34), which encodes hamartin [29], may function as a cell adhesion regulator through regulation of GTPase Rho and binding to activated ezrin-radixin-moesin proteins [30]. TSC2, located on chromosome 16 (16p 13.3) [31], encodes tuberin, which has Rheb (Ras homolog enriched in brain) GTPase-activating protein activity [32]. Together, tuberin and hamartin form a GTPase-activating protein complex that inhibits the effects of Rheb on mammalian target of rapamycin (mTOR) downstream-signalling pathways [33]. A mutation in either TSC1 or TSC2 results in inactivation of the tumour suppressor complex and persistent activation of Rheb and increased mTOR activity which, by downstream signalling effects, results in enhanced protein translation and cell proliferation through phosphorylation of S6, 4E-BP1 and other proteins [34].

In LAM, AMLs and lung and lymphatic lesions are composed of abnormal smooth muscle cells [8]. In addition to abnormal smooth muscle-like cells, AMLs are also composed of adipocytes and underdeveloped vascular structures [20]. Genetic analysis of sporadic LAM patients reveals TSC2 mutations in the cells of lung lesions, AMLs [35, 36] and lymph nodes [35]. Thus, the transformation of LAM cells by a TSC2 mutation appears to be the cause of sporadic LAM $[35,37,38]$ in accordance with the two-hit theory of KNUDSON [39].

Diagnosis of LAM is made by lung biopsy or a positive HRCT scan in association with an AML, chylous effusions or TSC [8]. In some cases, extrapulmonary LAM diagnosis precedes recognition of pulmonary LAM [12].

\section{Angiogenesis in TSC}

Patients with TSC may present with skin lesions such as forehead fibrous plaques, facial angiofibromas, ungual fibromas and Shagreen patches, in addition to brain and other manifestations [40, 41]. Immunohistochemical studies involving TSC neoplasms (kidney AMLs, cortical tumours and skin lesions) reported the expression and up-regulation of the angiogenic growth factor vascular endothelial growth factor (VEGF)-A [41, 42] and the vascular endothelial marker CD31 [41]. In contrast, evidence of angiogenesis (positive staining for CD31) was observed less in LAM lung foci [23], and serum levels of VEGF-A in LAM patients were no different from those of controls [43]. Collectively, data from these experiments suggest angiogenesis as a partial mechanism for pathogenesis of TSC.

\section{Lymphangiogenesis in LAM}

LAM cells express VEGF-C [23] and VEGF-D [43]. Podoplanin, a lymphatic marker recognised by the monoclonal antibody, D2-40, is expressed in LAM lesions and lung nodules [44]. Serum levels of VEGF-D are greater in patients with LAM than in healthy volunteers $[43,45,46]$. The expression of VEGF-C, VEGF-D and their ligand receptor, VEGF receptor (VEGFR)-3, in LAM lymphatic vessels is consistent with an active lymphangiogenic process within LAM foci. Correlations between lymphangiogenesis and severity of disease were observed in patients with LAM. A greater degree of lymphangiogenesis (quantified by expression of VEGF-C and VEGFR-3) [23] was associated with severe disease in LAM as measured by the LAM histologic score (LHS). LHS, a predictor of prognosis and time to transplant, is based on the involvement of lung tissue by cystic lesions and the infiltration by LAM cells as follows: LHS-1 <25\%; LSH-2 25$50 \%$; and LHS-3 >50\% [47]. Higher serum VEGF-D levels were found in patients with more severe lung destruction [45], as measured by CT grade [48], and also correlated with compromised pulmonary function $[43,45]$. These data suggest lymphatic involvement increases with disease progression. It has been reported that VEGF-C and VEGF-D induce proliferation of cells derived from LAM nodules via the activation of its cognate 
receptor VEGFR-3, and signalling of the Akt/mTOR/S6 downstream pathway [49].

VEGF-C, VEGFR-2 and VEGFR-3 are expressed in cortical brain tumours of TSC patients with a history of epileptic seizures [50]. The role of VEGF-C in cortical tubers of TSC may be to regulate epileptic activities through an inflammatory mechanism, rather than via its lymphangiogenic properties in TSC [50]. A study by Avila et al. [13] further supports the contrast between the angiogenic properties of TSC and lymphangiogenesis in LAM. Comparing CT scans of patients with sporadic LAM to those of LAM/TSC, sporadic LAM patients were observed to have a higher frequency of lymphatic manifestations (thoracic duct dilatation, ascites and lymphangioleiomyomas).

\section{LAM cell clusters}

LAM cell clusters (LCCs), which have been described as LAM cell aggregates surrounded by lymphatic endothelial cells, have been observed in dilated lymphatic vessels in proximity to lymph nodes or in the lungs [23] and chylous fluid [24]. Morphologically, LCCs are well-organised globular clusters $50-100 \mu \mathrm{m}$ in diameter found in chylous effusions $[51,52]$ and in the lung near areas of lymphatic vessel proliferation [51]. The clusters consist of two different cell types. The interior cells express smooth muscle antigens and are positive for HMB-45 [51, 52] and progesterone receptor [52]. The peripheral cells react with anti-VEGFR-3 antibodies and appear to be lymphatic endothelial cells [52].

\section{Lymphangiogenesis and the dissemination of LAM cells}

Although the hallmark of LAM is histologically benign lesions found in multiple organs, there is both pathological and genetic evidence that LAM cells possess metastatic properties. Initially, investigators reported mutations in the allografts of transplanted lungs that were identical to mutations found in the recipient patients with LAM [53, 54]. Other studies revealed the dissemination of LAM cells in the body fluids of LAM patients $[55,56]$ in a process similar to that occurring with neoplastic cells [57]. Proliferation of the neoplastic cell, cell survival in the circulation and recruitment to a metastatic site are important steps in the metastatic process [57]. CD44v6 (a molecular determinant of metastasis) is expressed in a subset of LAM lung-derived cells having loss of heterozygosity ( $\mathrm{LOH}$ ) at the TSC2 locus [58]. CD44 splicing has been associated with different signalling mechanisms, which may be involved in determining organ-specific metastasis [59]. In another study, both LAM cells (from explanted LAM lung) and AML cells were shown to possess the CXCR4 receptor. CXCL12 was immunohistochemically expressed in type II pneumocytes covering the LAM nodules and in the endothelial and adventitial cells surrounding AML vessels. In vivo, binding of CXCL12 to CXCR4 resulted in AML cell growth and reduced apoptosis [60]. Monocyte chemotactic protein (MCP)-1 induced in vitro migration of a subset of cultured cells from LAM lung explants having TSC2 LOH, which suggests MCP-1 may facilitate LAM cell movement and, thus, increase the potential for metastasis [61]. Collectively, these data support the metastatic potential of LAM cells.

The spread of primary tumour cells to other organ sites is an important factor in the progression of cancer, and is accomplished by direct invasion of local tissue or via the blood or lymphatic vessels. Lymphangiogenesis has been established as a major component of the metastatic process [62, 63], playing a significant metastatic role in multiple types of cancer, including breast cancer [64, 65], oesophageal cancer [66] and nonsmall cell lung carcinoma [67]. Lymphangiogenesis in LAM involves the axial lymphatic system with abundant lymphatic vessels in pulmonary and extrapulmonary LAM [12, 23, 24]. Lymphatic endothelial cells, identified by reactivity with antiVEGFR-3 antibodies, line the cystic or slit-like structures within LAM foci or nodules in lung and lymph nodes [23]. Lymphatic endothelial cells, in LAM foci of both nodules and lymph nodes, appear to partition LAM cells into bundles or discreet structures $[12,23]$. In contrast to normal lung, lymphatic vessels were observed in alveolar walls. In stages of advanced disease, LAM foci are observed projecting into lymphatic lumen and floating in lymphatic vessels [23]. Thus, it is conceivable that the lymphangiogenesis in LAM may facilitate the spread of LAM cells.

LAM cells possess metastatic properties, but are not morphologically malignant. The mechanism for metastasis in LAM remains elusive. In summary, important findings concerning lymphangiogenesis in LAM demonstrate that LAM cells react with antibodies to lymphatic growth factors VEGF-C/D, LCCs react with antibodies to VEGFR-3, LAM foci are traversed and delineated with lymphatic vessels and the axial lymphatic system is involved in LAM. LCCs are observed in chylous effusions, lung nodules and lymphatic vessels and fragment into LAM cells and lymphatic endothelial cells (LECs) in vitro $[23,24]$. KUMASAKA et al. [24] postulated, from these data, an invasion-independent metastatic process for LAM cells that would support the benign morphology of the LAM cell. In essence, since LAM cells are immunopositive to VEGF-D and VEGF-C and LAM cells proliferate in association with lymphangiogenesis, one result is a lymphatic network that aids the formation of LCCs. These LCCs eventually shed into the lymphatic circulation where they are transported to the pulmonary circulation via the jugulosubclavian connection. A similar outcome was observed in a murine mammary tumour model [68]. Two metastatic cell lines were established from naturally occurring mouse mammary tumours; clone MCH66 with poor invasive ability and clone MCH416 with high invasive ability. Cells cultured from clone MCH66, when injected into mice, developed tumour emboli surrounded by vascular endothelial cells. These emboli intravasated into newly formed blood vessels and metastasised to the lung. Tumour vascularity for this clone correlated to metastasis, and angiogenic activity was greater than for a control non-metastasising clone and clone MCH416. Proteins related to cell-stromal interaction and extracellular matrix assembly were differentially expressed in the $\mathrm{MCH} 66$ clonal cells. Based on these data, the authors suggested that the metastatic property of clone $\mathrm{MCH} 66$ was independent of cellular invasiveness, but dependent on angiogenesis and vascular remodelling [68]. A great deal remains to be learnt about LCCs, including further characterisation, their role in LAM pathogenesis and their potential diagnostic use.

An analysis of current studies in LAM by Yu and HENSKE [69] resulted in a comprehensive model for metastatic dissemination of LAM cells. In addition to the previously discussed lymphangiogenic driven model of KUMASAKA et al. [24], YU and HENSKE [69] cited data describing pro-metastatic cellular events in LAM and Tsc2-null Eker rats that may be important factors 
in promoting the dissemination of LAM cells. Among evidence cited, was loss of Tsc2 function through the association with Rho activity and increased migration [70]. Protease activity, including the expression of MMPs and the downregulation of their inhibitors, in LAM cells provide the capability of extracellular remodelling. Some LAM cells express oestrogen receptors and studies with oestrogen-treated Tsc2-null Eker rat-derived ELT3 leiomyoma cells illustrated resistance to programmed cell death, suggesting oestrogen may also have a survival effect on circulating LAM cells [69]. Taken together, these data prompted the authors to conclude that metastasis in LAM is a consequence of multiple factors involving mTOR activation, lymphangiogenesis, extracellular matrix remodelling and oestrogen-dependent cell survival.

\section{Diagnosis and treatment modalities}

The diagnosis of pulmonary LAM (no extrapulmonary involvement) can present problems due to the similarity to other cystic diseases (i.e. Langerhans' cell histiocytosis, emphysema, Sjögren syndrome, Birt-Hogg-Dubé syndrome). Serum VEGF-D levels appear to be significantly higher in LAM compared with other cystic diseases [46]. However, there is considerable overlap in the serum VEGF-D level between normal controls and LAM [45]. When serum VEGF-D levels of patients were stratified according to lymphatic involvement (defined by presence of lymphangioleiomyomas and/or adenopathy) significance was maintained for LAM patients with lymphatic involvement, but not for those with only pulmonary LAM or pulmonary LAM with AML (fig. 1) [45].

The presence of LCCs in chylous effusions may have diagnostic significance [51, 52]. The observation of LAM cells enveloped by lymphatic endothelial cells in chylous effusions appears to be specific and pathognomonic. Adenocarcinoma and malignant mesothelioma may form tumour cell clusters.

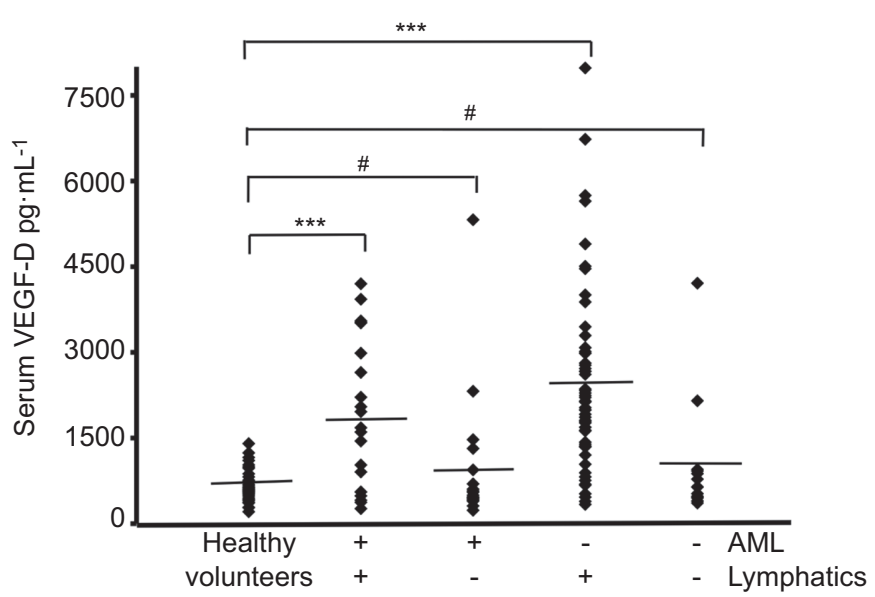

FIGURE 1. Serum levels of vascular endothelial growth factor (VEGF)-D in lymphangioleiomyomatosis. Serum VEGF-D levels in 111 patients with sporadic lymphangioleiomyomatosis were grouped on the basis of thoracic or abdominal lymphatic involvement (lymphangioleiomyomas and/or adenopathy: presence $n=77$; absence $n=34)$ and the presence $(n=40)$ or absence $(n=71)$ of renal angiomyolipomas (AML). All groups were compared to 40 healthy volunteers. Diamonds: serum measurement of VEGF-D from one patient or healthy volunteer — : mean values. ${ }^{*}: p=0.3 ;{ }^{* *}: p<0.001$. Reproduced from [45] with permission from the publisher.
There are distinct differences between LCCs to cell clusters found in malignant cancers that support the use of cytologic and immunocytochemical examinations of chylous effusions as a differential diagnostic tool for LAM.

As a consequence of the sex predilection for LAM disease, initial attempts to find treatments to prevent disease progression were hormone based [8] with inconsistent outcomes. These therapies included oophorectomy [71], the use of gonadotrophin-releasing hormone analogues [72] and progesterone $[9,73]$.

Clinical trials of sirolimus treatment for patients with LAM were initiated based on reports that the protein products of the TSC1/TSC2 complex are negative regulators of mTOR [33]. Cell size and number are regulated by mTOR via downstream signalling of p70 S6 and 4E-BP1 [32, 33, 74]. Loss of TSC function activates the mTOR pathway. Results from a sirolimus clinical trial [75] and a study cohort consisting of patients with LAM using off-label sirolimus [76] showed an improvement or stabilisation $[75,76]$ in lung function (fig. 2) and reduced serum VEGF-D levels [75]. Sirolimus treatment is now being advised, in general, for LAM patients suffering from severe disease [75]. AMLs, a benign tumour, may cause serious haemorrhaging which is commonly resolved with arterial embolisation or kidney-sparing surgery. Reports from clinical drug trials for patients with LAM targeting mTOR indicated a 50\% decline in the size of AMLs, but tumours increased in size on withdrawal of medication [77]. Interestingly, in an off-label study, sirolimus treatment completely resolved or reduced lymphangioleiomyomas and effusions in patients with LAM [76]. Chemical pleurodesis has been advised for the management of pneumothorax as the best choice in preventing recurrence of pneumothorax, although it is associated with perioperative bleeding $[78,79]$.

\section{Summary}

Lymphatic involvement in LAM encompasses the proximal and distal regions of the axial lymphatic system. Lymphatic structures traverse LAM foci and demarcate LAM cells into bundles. Lymphatic vessels invade vascular walls and the pulmonary interstitium, and LCC s can be seen in lymphatic vessels. Clinical manifestations in LAM patients, such as adenopathy, lymphangioleiomyomas and chylous effusions, are a result of dilatation and/or obstruction of lymphatics caused by proliferation of LAM cells. Lymphatic biomarkers include serum VEGF-D levels, which are associated with lymphatic involvement; the presence of LCCs may prove to be an effective diagnostic tool. Lymphangiogenesis in LAM appears to be mediated through the expression of VEGF-C and VEGF-D via VEGFR-3. The envelopment of LAM cells by lymphatic vessels and eventual shedding of LCCs into the lymphatic circulation is a possible mechanism for the metastasis of LAM lesions to other organs.

\section{IDIOPATHIC PULMONARY FIBROSIS}

Idiopathic pulmonary fibrosis (IPF) is a progressive, often fatal lung disease of unknown aetiology. In the USA, the most recent data show a prevalence ranging from 14 to 42.7 per 100,000 population and an incidence ranging from 6.8 to 16.3 cases per 100,000 [80]. In Europe, IPF is estimated to affect $80,000-85,000$ people [81]. The length of time before diagnosis can sometimes be measured in decades [82]. Over the last few 

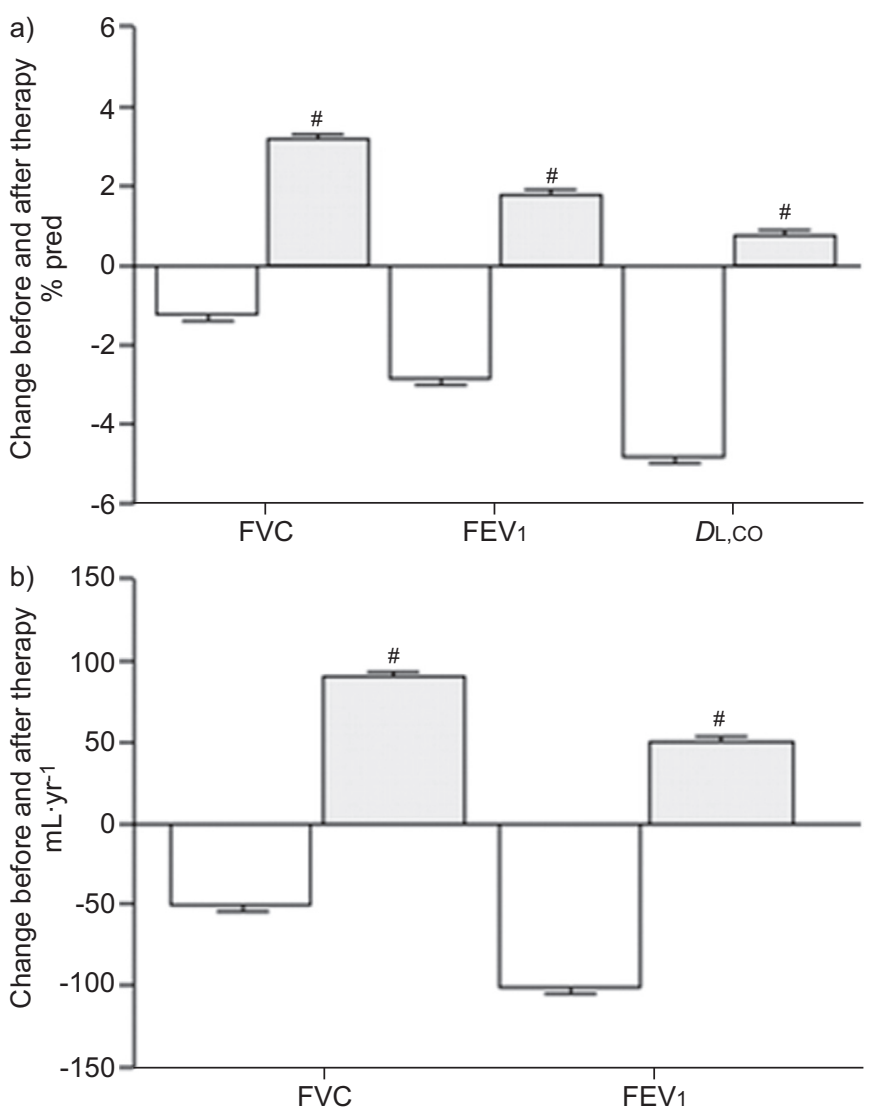

FIGURE 2. Mean annual changes in forced vital capacity (FVC), forced expiratory volume in $1 \mathrm{~s}\left(\mathrm{FEV}_{1}\right)$ and diffusing capacity of the lung for carbon monoxide $(D\llcorner, C O)$ before (white) and after sirolimus (grey) therapy in patients with lymphangioleiomyomatosis. Data show sirolimius therapy resulted in an increase in FVC, FEV1 and DL,CO. Mixed-effect models were used for statistical analysis. \#: $\mathrm{n}=18$ patients. Reproduced from [76].

years clinical trials have shown some benefit for different agents in the treatment of patients with IPF. The European IFIGENIA trial, investigating the combination of azathioprine and prednisone without or with $\mathrm{N}$-acetylcysteine (NAC), showed that the addition of NAC had a beneficial effect on the decline in vital capacity [83]. However, an interim analysis of the currently enrolling PANTHER trial comparing azathioprine, prednisone and NAC to NAC alone or placebo showed an increase in mortality, serious adverse events and drug discontinuation without benefit in the triple therapy arm of the trial. The National Heart, Lung, and Blood Institute stopped recruitment in this treatment arm, the other two arms comparing NAC to placebo continue patient recruitment [84]. Recently, in randomised clinical trials pirfenidone showed the ability to slow decline in forced vital capacity in IPF $[85,86]$. Tyrosine kinase inhibition also showed promise in the control of lung function decline and rate of IPF exacerbation [87]. However, the only currently effective therapy is lung transplantation [88].

The pathogenesis of IPF is not completely understood. Currently, IPF is believed to be a disease of epithelial injury and aberrant repair mechanisms, leading to a mesenchymal transition, which in turn results in fibroblast accumulation and collagen deposition [89]. Recent evidence highlights the importance of genetic background in disease pathogenesis, in cases of familial and sporadic IPF [90-92].

A role for vascular remodelling in IPF has long been suspected. The distribution of blood vessels in the IPF lung mirrors the temporal and spatial heterogeneity of disease. The role of neovascularisation and angiogenic growth factors remains controversial. For instance, VEGF-A, an angiogenic growth factor, was highly expressed in endothelial cells and alveolar type II cells, but not by fibroblasts in areas of fibrosis [93]. The distribution and content of the blood vasculature is heterogeneous. One group found increased neovascularisation with marked increase in blood vessels in areas of severe lung destruction [94], while others found an increase in areas of low-grade fibrosis [93].

Thus, IPF may be similar to other chronic inflammatory processes that are associated with angiogenesis. Early inhibition of vascular remodelling in an animal model of lung injury resulted in less fibrosis [95], while depletion of inflammatory cellderived VEGF-A led to decreased vasculature and worsening fibrosis [96]. While these results are contradictory, they highlight the importance of timing the inhibition of angiogenesis.

\section{Rationale for the study of lymphatics in IPF}

In inflammation and malignancy, angiogenesis and lymphangiogenesis are closely associated [97, 98]; further angiogenesis is a key feature of IPF. In animal models and in human disease, disruption of the lymphatic circulation results in the development of fibrosis, such as in the case of radical lymph node dissection or in Milroy's disease, which is caused by mutations in the VEGFR-3 receptor [99].

In the normal lung, it appears that lymphatic vessels exist in proximity to the major blood vessels and airways [100-102]. With some exceptions, most authors agree that there are no lymphatic vessels in the alveolar spaces. In pig lung, MARCHETTI et al. [101] did not find any lymphatic vessels between alveoli. PEAO et al. [102] and HAINIS et al. [100] did not find evidence of alveolar lymphatics in mouse and rat lungs, respectively. LEAK [103] described the presence of juxta-alveolar lymphatics separated from the alveolar space by the alveolar wall and a thin layer of connective tissue.

In the normal human lung, multiple studies have confirmed a pattern of lymphatic distribution. Lymphatic vessels are found in close proximity to the bronchovascular tree and were absent or rare in the alveolar spaces [98]. In their study of lymphangiogenesis in IPF, EBINA et al. [104] showed that in the normal lung, no lymphatic vessels were present in the alveolar septa. KAMBOUCHNER et al. [105] examined normal lung adjacent to excised tumours and found lymphatic vessels to be associated with as much as $19 \%$ of alveolar spaces.

In a previous study by our group [106], we examined the distribution of lymphatic vessels in normal and IPF lung from subjects with varying degrees of disease severity. We found that in normal lung, lymphatic vessels reactive with anti-D2-40 antibodies were present alongside large blood vessels (reactive with anti-CD-34 antibodies), but were absent from alveolar spaces. In marked contrast, in the IPF lung, lymphatic vessels were present in the alveolar spaces (fig. 3a), as well as in 


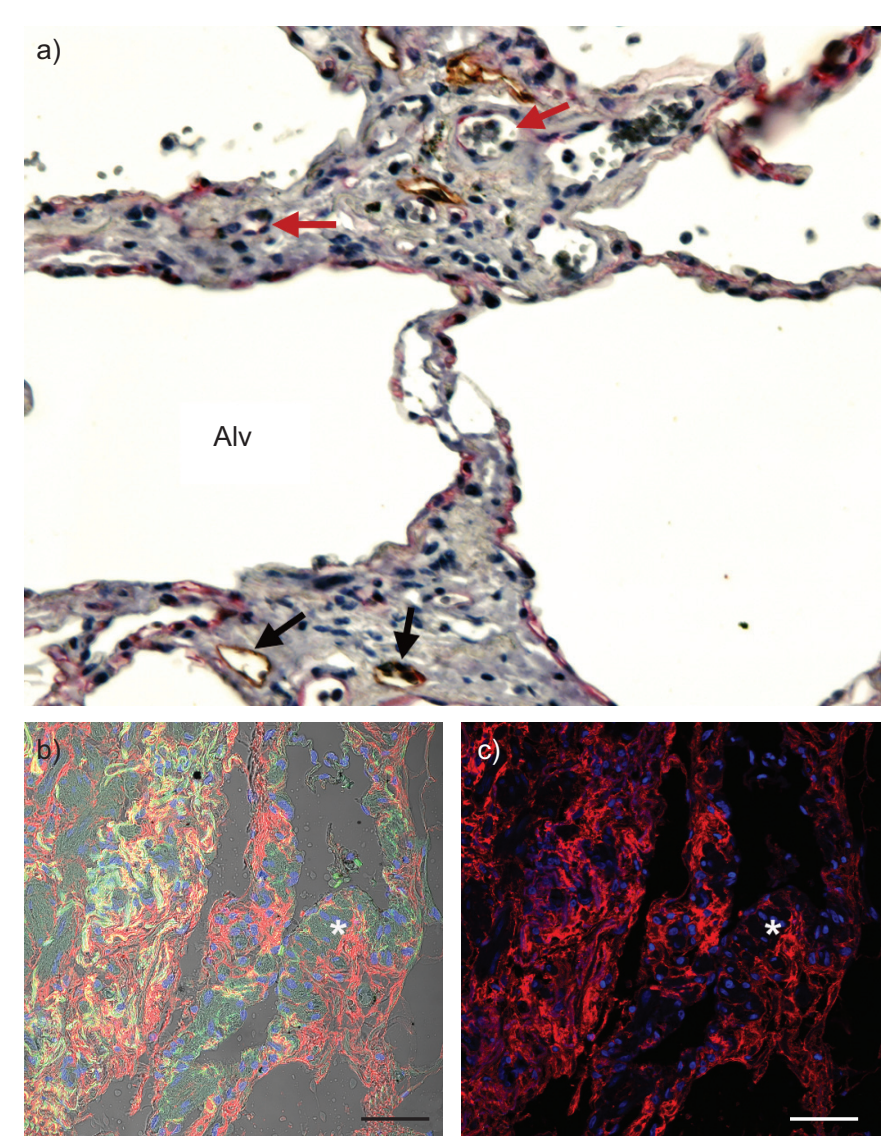

FIGURE 3. Alveolar lymphangiogenesis is a feature of idiopathic pulmonary fibrosis (IPF). a) Tissue sections reacted with anti-D2-40 (brown) and anti-CD34 (red) antibodies. Lymphatic vessels (D2-40+; black arrows) and blood vessels (CD$34+$; red arrows) are visible adjacent to the alveolar spaces (Alv) in early stages of disease. b, c) Presence of hyaluronic acid in IPF lung. Immunofluorescence staining with hyaluronan-binding protein of paraffin-embedded sections of IPF lung tissue shows hyaluronic acid (red) in a representative single confocal microscopy optical section. Fibroblastic areas $\left({ }^{*}\right)$ displaying positive staining for hyaluronic acid are presented as merged images of hyaluronic acid and 4',6-diamidino-2phenylindole (DAPI; blue) with (b) or without (c) an auto-fluorescence signal (green) and differential influence contrast. Cell nuclei were stained with DAPI. Scale bars $=50 \mu \mathrm{m}$

fibrotic areas. One exception was the fibroblastic foci, which did not contain lymphatic vessels. YAMASHITA et al. [98] obtained similar results in their study of lymphangiogenesis during diffuse alveolar damage (DAD); fibroblastic foci lacked lymphatic vessels and alveolar lymphangiogenesis was a key feature of lung fibrosis in diffuse alveolar damage.

By morphometric analysis, we found that with worsening IPF disease severity there is a significant increase in total area, mean area and perimeter of lymphatic vessels, but number of vessels did not change. This is the opposite of blood capillaries where numbers increase but size does not change [106]. Similarly, in the study of fibrosis during DAD, capillaries appeared earlier than lymphatic vessels during the proliferative phase. Capillary density decreased with end-stage fibrosis, while lymphatic density did not [98].
EBINA et al. [104] performed a detailed analysis of the lymphatic vasculature in IPF lung and observed that fibroblastic foci were devoid of lymphatic vessels. However, alveolar lymphangiogenesis did not seem to be a key part of the fibrotic process. Furthermore, in the normal non-fibrotic areas of the IPF lung, new lymphatic vasculature was found in the alveolar lesion [104]. In IPF lung, lymphatic vessels were fragmented with a marked decline in subpleural lymphatic vessels [104].

\section{Role of hyaluronan in Iymphangiogenesis in IPF}

Factors present in the alveolar space play a key role in lymphangiogenesis in IPF. Bronchoalveolar lavage fluid (BALF) isolated from subjects with IPF caused greater migration of LEC than BALF from healthy volunteers. An analysis of potential factors in the BALF from subjects with IPF that could contribute to lymphangiogenesis showed that the VEGF family of proteins seemed not to be critical. Consistent with previous reports [94, 107, 108], VEGF-A content was lower in BALF from subjects with IPF than healthy controls. VEGF-C levels, the most potent lymphangiogenic growth factor, were also lower in the IPF BALF. VEGF-D levels were similar to healthy controls. In addition, levels of factors known to either induce lymphangiogenesis, such as fibroblast growth factor [109], or stabilise vascular tubes, such as tissue inhibitor of metalloproteinases (TIMP)-2 [110], were similar between IPF and healthy control BALF. Factors present at greater concentrations in IPF BALF were hepatocyte growth factor (HGF) [106, 111], TIMP-1 and CCL2 [112, 113]. HGF is known to induce lymphangiogenesis in inflammation [114]. Incubation of IPF BALF with function-blocking antibodies to HGF, TIMP-1 or CCL2 did not affect LEC migration [106].

BALF from subjects with IPF is enriched in hyaluronan [115], a critical mediator of lung injury and repair through CD44 receptors or through Toll-like receptors [116, 117]. Furthermore, hyaluronan induced angiogenesis in an animal model of fibrosis [118]. In addition, in animal tumour models, hyaluronan has been shown to induce intratumoral lymphangiogenesis, not angiogenesis $[119,120]$. IPF lung sections reacted with a hyaluronan-binding protein (fig. $3 b$ and c). In addition, treatment of IPF BALF with hyaluronidase, which generates shortfragment hyaluronan, increased LEC migration and proliferation. The addition of short-fragment hyaluronan to healthy volunteer BALF resulted in increased LEC migration. Taken together, these data show that short-fragment hyaluronan plays a critical role in the lymphangiogenic process in IPF. Hyaluronan has multiple receptors on the surface of endothelial cells, including LYVE-1. These receptors are functionally redundant [121]. The mechanisms by which hyaluronan induces lymphangiogenesis remains an area of active research.

\section{Role for progenitor endothelial cells}

The existence of a lymphatic endothelial progenitor cell has been speculated in work by SALVEN et al. [122] who showed that CD $34^{+} / \mathrm{CD}_{133^{+}} / \mathrm{VEGFR}-3^{+}$cells derived from human fetal liver express LYVE-1 and podoplanin when cultured, suggesting that they have the ability to differentiate into LEC. Moreover, studies in a cornea inflammation model showed that bone marrowderived cells incorporated into newly formed corneal lymphatic vessels [123]. MARUYAMA et al. [124] showed that thioglycolateactivated $\mathrm{CD} 11 \mathrm{~b}^{+}$macrophages were able to transdifferentiate 


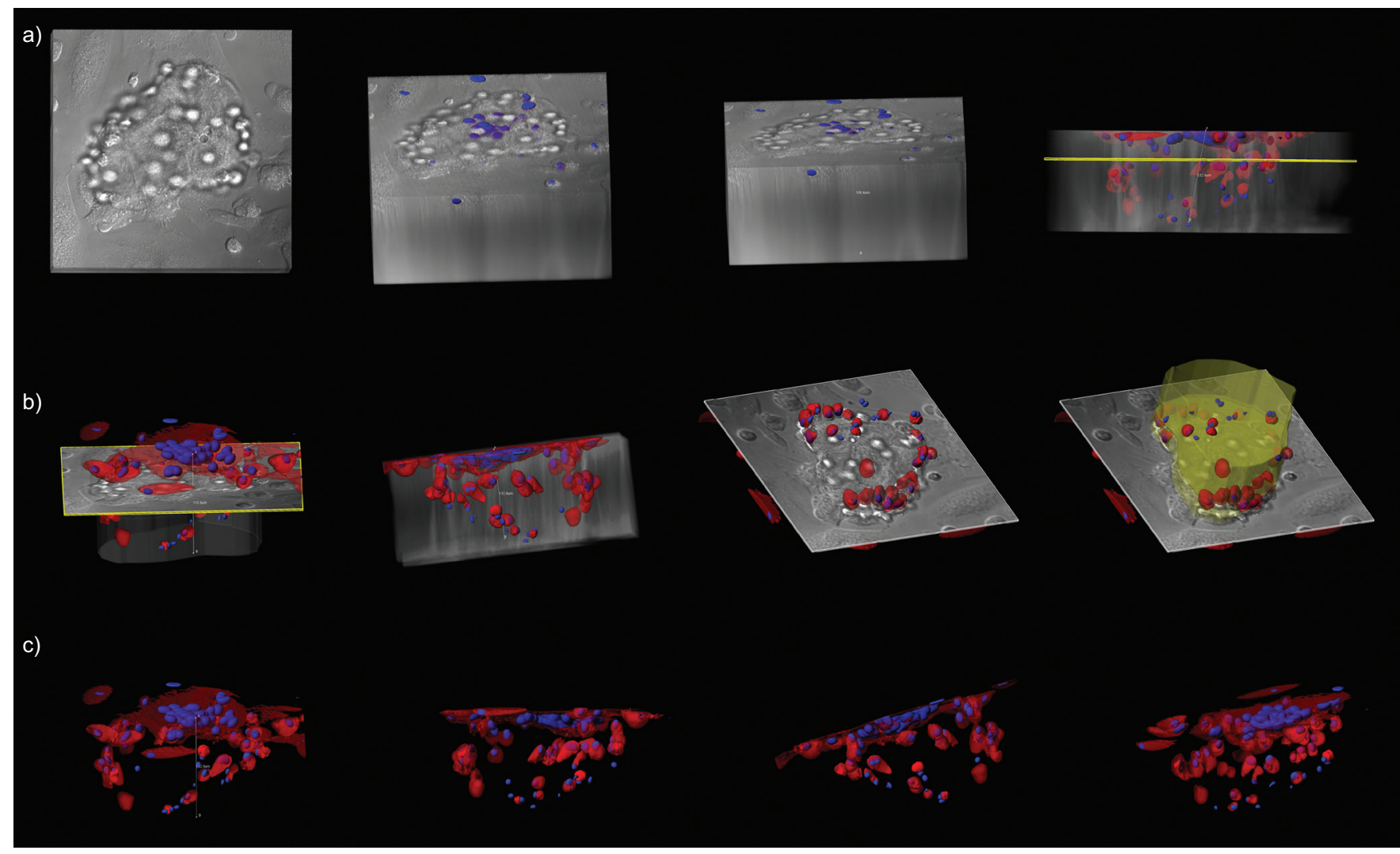

FIGURE 4. $\mathrm{CD}_{11} \mathrm{~b}^{+}$alveolar macrophages in idiopathic pulmonary fibrosis (IPF) develop tube-like structures in vitro. CD11 $\mathrm{b}^{+}$alveolar macrophages were cultured in Matrigel $\S_{\circledast}$ for up to 31 days and inspected under white light or after fluorescent-labelling of cytoplasm (CellTracker ${ }^{\mathrm{TM}}$ Orange CMTMR; Invitrogen, Carlsbad, CA, USA) and nuclei (Hoechst stain; Invitrogen). Large tube-like structures (150 $\mu \mathrm{m}$ in diameter) were observed when cells from subjects with IPF were cultured in Matrigelæ (BD Biosciences, San Jose, CA, USA) for 30 days. A series of confocal images were reconstructed in three-dimensional renderings and representative snapshots of tubular structures are presented as overlaid fluorescence $a, b$ ) with or c) without differential influence contrast.

into LEC in cornea inflammation models. The first evidence in humans of circulating progenitor lymphatic endothelial cells came from the work of KERJASCHKI et al. [125] who showed the presence of LEC from the recipient in sex-mismatched kidney transplants.

In contrast, another group found that $\mathrm{CD}_{11 \mathrm{~b}^{+}}$macrophages were critical for lymphangiogenesis during inflammation and cancer. These macrophages are responsible for the production of VEGF (e.g. VEGF-A/C/D). These macrophages did not differentiate into LEC [126-128].

More recently, a study established that bone marrow-derived $\mathrm{CD}_{11 b^{+} / \text {podoplanin }}{ }^{+}$cells or similar cells from peripheral blood can differentiate into LEC, both in vitro and in vivo [129]. Bone marrow-derived podoplanin-positive $\mathrm{CD}_{11 b^{+}}$cells differentiated into LEC, with expression of Prox-1 and LYVE-1 and downregulation of CD45. The newly formed alveolar lymphatics of IPF did not connect to the main lymphatic system $[104,106]$, raising the question about the origin of the lymphatic endothelial cells, since in cancer and inflammation, newly formed vessels arise from existing ones [130]. Alveolar macrophages are the most abundant cell in the alveolar space, and the CD11 subfamily of macrophages was found to be more abundant in IPF compared with other interstitial lung diseases [131]. Thus $\mathrm{CD} 45^{+} / \mathrm{CD} 14^{+} / \mathrm{CD} 11 \mathrm{~b}^{+}$macrophages isolated from
BALF of subjects with IPF and not from healthy volunteers differentiated into LEC after growth in Matrigel ${ }_{\circledR}$ for 30 days (fig. 4). After 30 days, these cells expressed LEC markers LYVE-1 and podoplanin while CD11 ${ }^{+}$macrophages isolated from healthy volunteers expressed LYVE-1 but failed to form tube-like structures when cultured in vitro for 30 days.

The role and function of the lymphatic circulation in the fibrotic process remains unclear [132]. LEC secrete CCL21, a ligand for CCR7, which was elevated in IPF BALF [106]. In IPF, dendritic cells are recruited into the IPF lung after stimulation with CCL21 [133]. In addition, CCL21 induced the proliferation of IPF fibroblasts [134]. Finally, it is well known that transforming growth factor- $\beta$ is a potent inhibitor of prox-1 expression, resulting in inhibition of lymphangiogenesis [135]. Further research is needed to understand the crosstalk between the lymphatic vasculature and fibroblasts, which will ultimately result in a better understanding of the role of the lymphatic circulation in fibrosis in general and in IPF in particular.

\section{SUPPORT STATEMENT}

The writing of this manuscript was supported by the Intramural Research Program, National Institutes of Health, National Heart, Lung, and Blood Institute (Bethesda, MD, USA). S. El-Chemaly is supported by a grant from NIH/NHLBI K22HL92223-01. 


\section{STATEMENT OF INTEREST}

None declared.

\section{ACKNOWLEDGEMENTS}

We thank D. Malide of the Light Microscopy Core (NIH/NHLBI, Bethesda, MD, USA) for her invaluable assistance in microscopy experiments and image analysis. We also thank G. Pacheco-Rodriguez (Cardiovascular and Pulmonary Branch, National Heart, Lung and Blood Institute, National Institutes of Health, Bethesda, MD, USA) for formatting the figures.

\section{REFERENCES}

1 Kitaichi $\mathrm{M}$, Nishimura $\mathrm{K}$, Itoh $\mathrm{H}$, et al. Pulmonary lymphangioleiomyomatosis: a report of 46 patients including a clinicopathologic study of prognostic factors. Am J Respir Crit Care Med 1995; 151: 527-533.

2 Chu S, Horiba K, Usuki J, et al. Comprehensive evaluation of 35 patients with lymphangioleiomyomatosis. Chest 1999; 115: 1041-1052.

3 Urban T, Lazor R, Lacronique J, et al. Pulmonary lymphangioleiomyomatosis: a study of 69 patients. Medicine 1999; 78: 321-337.

4 Johnson SR, Tattersfield AD. Clinical experience of lymphangioleiomyomatosis in the UK. Thorax 2000; 55: 1052-1057.

5 Ryu J, Moss J, Beck G, et al. The NHLBI lymphangioleiomyomatosis registry: characteristics of 230 patients at enrollment. Am I Respir Crit Care Med 2006; 173: 105-111.

6 Steagall WK, Taveira-DaSilva A, Moss J. Clinical and molecular insights into lymphangioleiomyomatosis. Sarcoidosis Vasc Diffuse Lung Dis 2005; 22: Suppl. 1, S49-S66.

7 Crino $\mathrm{P}$, Mathanson K, Henske E. The tuberous sclerosis complex. N Engl J Med 2006; 355: 1345-1356.

8 Taveira-DaSilva A, Steagall WK, Moss J. Lymphangioleiomyomatosis. Cancer Control 2006; 13: 276-285.

9 Taveira-DaSilva A, Stylianou M, Hedin C, et al. Decline in lung function in patients with lymphangioleiomyomatosis treated with or without progesterone. Chest 2004; 126: 1867-1874.

10 Johnson DR, Whale C, Hubbard R, et al. Survival and disease progression in UK patients with lymphangioleiomyomatosis. Thorax 2004; 59: 800-803.

11 Avila NA, Kelly J, Chu S, et al. Lymphangioleiomyomatosis: abdominopelvic CT and US findings. Radiology 2000; 216: 147-153.

12 Matsui K, Tatsuguchi A, Valencia J, et al. Extrapulmonary lymphangioleiomyomatosis (LAM): clinicopathologic features in 22 cases. Hum Pathol 2000; 31: 1242-1248.

13 Avila NA, Dwyer A, Rabel A, et al. Sporadic lymphangioleiomyomatosis and tuberous sclerosis complex with lymphangioleiomyomatosis: comparison of CT features. Radiology 2007; 242: 277-285.

14 Cornog J, Enterline H. Lymphangiomyoma, a benign lesion of chyliferous lymphatics synonymous with lymphangiopericytoma. Cancer 1966; 19: 1909-1930.

15 Peh W, Law S, Fok M, et al. Case report: lymphangiomoyomatosis with spontaneous peritoneal rupture. Br J Radiol 1994; 67: 605-608.

16 Corrin B, Leibow A, Friedman P. Pulmonary lymphangiomyomatosis: a review. Am J Pathol 1975; 79: 347-382.

17 Avila NA, Bechtle J, Dwyer A, et al. Lymphangioleiomyomatosis: CT of diurnal variation of lymphangioleiomyomas. Radiology 2001; 221: 415-421.

18 Avila NA, Dwyer A, Murphy-Johnson D, et al. Sonography of lymphangioleiomyoma in lymphangioleiomyomatosis: demonstration of diurnal variation in lesion size. AJR Am J Roentgenol 2005; 184: 459-484.

19 Matsui K, Riemenschneider W, Hilbert S, et al. Hyperplasia of type II pneumocytes in pulmonary lymphangioleiomyomatosis: immunohistochemical and electron microscopic study. Arch Pathol Lab Med 2000; 124: 1642-1648.

20 Ferrans V, Yu Z-X, Nelson W, et al. Lymphangioleiomyomatosis (LAM): a review of clinical and morphological features. J Nippon Med Sch 2000; 67: 311-329.

21 Matsumoto Y, Horiba K, Usuki J, et al. Markers of cell proliferation and expression of melanosomal antigen in lymphangioleiomyomatosis. Am I Respir Cell Mol Biol 1999; 21: 327-336.

22 Adema G, De Boer A, Vogel A, et al. Molecular characterization of the melanocyte lineage-specific antigen gp100. J Biol Chem 1994; 269: 20126-20133.

23 Kumasaka T, Seyama K, Mitani K, et al. Lymphangiogenesis in lymphangioleiomyomatosis: its implication in the progression of lymphangioleiomyomatosis. Am J Surg Pathol 2004; 28: 1007-1016.

24 Kumasaka T, Seyama K, Mitani K, et al. Lymphangiogenesismediated shedding of LAM cell clusters as a mechanism for dissemination in lymphangioleiomyomatosis. Am J Surg Pathol 2005; 29: 1356-1366.

25 Moss J, Avila NA, Barnes $\mathrm{P}$, et al. Prevalence and clinical characteristics of lymphangioleiomyomatosis (LAM) in patients with tuberous sclerosis complex. Am J Respir Crit Care Med 2001; 163: 669-671.

26 Costello L, Hartman T, Ryu J. High frequency of pulmonary lymphangioleiomyomatosis in women with tuberous sclerosis complex. Mayo Clin Proc 2000; 75: 591-594.

27 Franz D, Brody A, Meyer C, et al. Mutational and radiographic analysis of pulmonary disease consistent with lymphangioleiomyomatosis and micronodular pneumocyte hyperplasia in women with tuberous sclerosis. Am J Respir Crit Care Med 2001; 164: 661-668

28 Sampson J, Harris P. The molecular genetics of tuberous sclerosis. Hum Mol Genet 1994; 3: 1477-1480.

29 van Slegtenhorst $M$, de Hoogt R, Hermans $C$, et al. Identification of the tuberous sclerosis gene TSC1 on chromosome 9q34. Science 1994; 277: 805-808.

30 Lamb R, Roy C, Diefenbach TJ, et al. The TSC1 tumour suppressor hamartin regulates cell adhesion through ERM proteins and the GTPase Rho. Nat Cell Biol 2000; 2: 281-287.

31 The European Chromosome 16 Tuberous Sclerosis Consortium. Identification and characterization of the tuberous sclerosis gene on chromosome 16. Cell 1993; 75: 1305-1315.

32 Tee AR, Manning BD, Roux PP, et al. Tuberous sclerosis complex gene products, tuberin and hamartin, control mTOR signaling by acting as a GTPase-activating protein complex toward Rheb. Curr Biol 2003; 13: 1259-1268.

33 Tee AR, Fingar DC, Manning BD, et al. Tuberous sclerosis complex-1 and -2 gene products function together to inhibit mammalian target of rapamycin (mTOR)-mediated downstream signaling. Proc Natl Acad Sci USA 2002; 99: 13571-13576.

34 Fingar DC, Salama S, Tsou C, et al. Mammalian cell size is controlled by mTOR and its downstream targets S6K1 and 4EBP1/eIF4E. Genes Dev 2002; 16: 1472-1487.

35 Smolarek T, Wessner L, McCormack F, et al. Evidence that lymphangiomyomatosis is caused by TSC2 mutations: chromosome 16 p13 loss of heterozygosity in angiomyolipomas and lymph nodes from women with lymphangiomyomatosis. Am J Hum Genet 1998; 62: 810-815.

36 Astrinidis A, Khare L, Carsillo T, et al. Mutational analysis of the tuberous sclerosis gene TSC2 in patients with pulmonary lymphangioleiomyomatosis. I Med Genet 2000; 37: 55-57.

37 Sato T, Seyama K, Fujii H, et al. Mutation analysis of the TSC1 and TSC2 genes in Japanese patients with pulmonary lymphangioleiomyomatosis. J Hum Genet 2001; 47: 20-28.

38 Carsillo T, Astrinidis A, Henske E. Mutations in the tuberous sclerosis complex gene TSC2 are a cause of sporadic pulmonary 
lymphangioleiomyomatosis. Proc Natl Acad Sci USA 2000; 97: 6085-6090.

39 Knudson AG Jr. Mutation and cancer: statistical study of retinoblastoma. Proc Nat Acad Sci USA 1971; 68: 820-823.

40 Webb D, Clarke A, Fryer A, et al. The cutaneous features of tuberous sclerosis: a population study. Br J Dermatol 1996; 135: $1-5$.

41 Arbiser JL, Brat D, Hunter S, et al. Tuberous sclerosis-associated lesions of the kidney, brain, and skin are angiogenic neoplasms. J Am Acad Dermatol 2002; 46: 376-380.

42 Nguyen-Vu PA, Fackler I, Rust A, et al. Loss of tuberin, the tuberous-sclerosis-complex-2 gene product is associated with angiogenesis. J Cutan Pathol 2001; 28: 470-475.

43 Seyama K, Kumasaka T, Souma S, et al. Vascular endothelial growth factor-D is increased in serum of patients with lymphangioleiomyomatosis. Lymphat Res Biol 2006; 3: 143-152.

44 Hansen T, Katenkamp K, Bittinger F, et al. D2-40 labeling in lymphangiomyoma/lymphangiomyomatosis of the soft tissue: further evidence of lymphangiogenic tumor histogenesis. Virchows Arch 2007; 450: 449-453.

45 Glasgow CG, Avila NA, Lin J-P, et al. Serum vascular endothelial growth factor-D levels in patients with lymphangioleiomyomatosis reflect lymphatic involvement. Chest 2009; 135: 1293-1300.

46 Young L, VanDyke R, Gulleman O, et al. Serum vascular endothelial growth factor-D prospectively distinguishes lymphangioleiomyomatosis from other diseases. Chest 2010; 138: 674-681.

47 Matsui K, Beasley MB, Nelson W, et al. Prognostic significance of pulmonary lymphangioleiomyomatosis histologic score. Am J Surg Pathol 2001; 25: 479-484.

48 Avila NA, Chen C, Chu S, et al. Pulmonary lymphangioleiomyomatosis: correlation of ventilation-perfusion scintigraphy, chest radiography, and $\mathrm{CT}$ with pulmonary function tests. Radiology 2000; 214: 441-446.

49 Issaka R, Gupta S, Liu G, et al. Vascular endothelial growth factors $\mathrm{C}$ and $\mathrm{D}$ induces proliferation of lymphangioleiomyomatosis cells through autocrine crosstalk with endothelium. Am J Pathol 2009; 175: 1410-1420.

50 Zhang C-Q, Shu H-F, Yin Q, et al. Expression and cellular distribution of vascular endothelial growth factor-C system in cortical tubers of the tuberous sclerosis complex. Brain Pathol 2012; 22: 205-218.

51 Itami M, Teshima S, Asakuma Y, et al. Pulmonary lymphangiomyomatosis diagnosed by effusion cytology. Acta Cytol 1997; 41: 522-528.

52 Mitani K, Kumasaka T, Takemura H, et al. Cytologic, immunocytochemical and ultrastructural characterization of lymphangioleiomyomatosis cell clusters in chylous effusions of patients with lymphangioleiomyomatosis. Acta Cytol 2009; 53: 402-409.

53 Bittmann I, Rolf B, Amann G, et al. Recurrence of lymphangioleiomyomatosis after single lung transplantation: new insights into pathogenesis. Hum Pathol 2003; 34: 95-98.

54 Karbowniczek M, Astrinidis A, Balsara BR, et al. Recurrent lymphangiomyomatosis after transplantation: genetic analyses reveal a metastatic mechanism. Am J Respir Crit Care Med 2003; 167: 976-982.

55 Crooks D, Pacheco-Rodriguez G, DeCastro R, et al. Molecular and genetic analysis of disseminated neoplastic cells in lymphangioleiomyomatosis. Proc Natl Acad Sci 2004; 101: 17462-17467.

56 Cai X, Pacheco-Rodriguez G, Fan Q-Y, et al. Phenotypic characterization of disseminated cells with TSC2 loss of heterozygosity in patients with lymphangioleiomyomatosis. Am J Respir Crit Care Med 2010; 182: 1410-1418.

57 Chambers A, Groom A, MacDonald I. Dissemination and growth of cancer cells in metastatic sites. Nat Rev Cancer 2002; 2: 563-572.

58 Pacheco-Rodriguez G, Steagall WK, Crooks DM, et al. TSC2 loss in lymphangioleiomyomatosis cells correlated with expression of
CD44v6, a molecular determinant of metastasis. Cancer Res 2007; 67: 10573-10581.

59 Marhaba R, Zoller M. Cd44 in cancer progression: adhesion, migration and growth regulation. J Mol Histol 2004; 35: 135-138.

60 Clements D, Markwick LJ, Puri N, et al. Role of the CXCR4/ CXCL12 axis in lymphangioleiomyomatosis and angiomyolipoma. J Immunol 2010; 185: 1812-1821.

61 Pacheco-Rodriguez G, Kumaki F, Steagall WK, et al. Chemokineenhanced chemotaxis of lymphangioleiomyomatosis cells with mutations in the tumor suppressor TSC2 gene. J Immunol 2009; 182: 1270-1277.

62 Stacker S, Baldwin M, Achen M. The role of tumor lymphangiogeneis in metastatic spread. FASEB J 2002; 16: 922-934.

63 Karpanen T, Alitalo K. Molecular biology and pathology of lymphangiogenesis. Annu Rev Pathol 2008; 3: 367-397.

64 Skobe M, Hawighorst T, Jackson DG, et al. Induction of tumor lymphangiogenesis by VEGF-C promotes breast cancer metastasis. Nat Med 2001; 7: 192-198.

65 Ran S, Volk L, Hall K, et al. Lymphangiogenesis and lymphatic metastasis in breast cancer. Pathophysiology 2010; 17: 229-251.

66 Kitadai Y, Amioka T, Haruma K, et al. Clinicopathological significance of vascular endothelial growth factor (VEGF)-C in human esophageal squamous cell carcinomas. Int J Cancer 2001; 93: 662-666.

67 Arinaga M, Noguchi T, Takeno S, et al. Clinical significance of vascular endothelial growth factor $C$ and vascular endothelial growth factor receptor 3 in patients with nonsmall cell lung carcinoma. Cancer 2003; 97: 457-464.

68 Sugino T, Kusakabe T, Hoshi N, et al. An invasion-independent pathway of blood-borne metastasis: a new murine mammary tumor model. Am J Pathol 2002; 160: 1973-1980.

$69 \mathrm{Yu}$ J, Henske EP. mTOR activation, lymphangiogenesis, and estrogen-mediated cell survival: the "perfect storm" of prometastatic factors in LAM pathogenesis. Lymphat Res Biol 2010; 8: 43-49.

70 Astrinidis A, Cash TP, Hunter DS, et al. Tuberin, the tuberous sclerosis complex 2 tumor suppressor gene product, regulates Rho activation, cell adhesion and migration. Oncogene 2002; 21: 8470-8476.

71 Taylor JR, Ryu J, Colby TV, et al. Lymphangioleiomyomatosis: clinical course in 32 patients. N Engl J Med 1990; 323: 1254-1260.

72 Harari S, Cassandro R, Chiodini J, et al. Effect of a gonadotrophinreleasing hormone analogue on lung function in lymphangioleiomyomatosis. Chest 2008; 133: 448-454.

73 Johnson SR, Tattersfield AE. Decline in lung function in lymphangioleiomyomatosis: relation to menopause and progesterone treatment. Am J Respir Crit Care Med 1999; 160: 628-633.

74 Goncharova EA, Goncharov DA, Eszterhas A, et al. Tuberin regulates p70 S6 activation and ribosomal protein $\mathrm{S} 6$ phosphorylation. J Biol Chem 2002; 277: 30958-30967.

75 McCormack FX, Inioue Y, Moss J, et al. Efficacy and safety of sirolimus in lymphangioleiomyomatosis. N Engl J Med 2011; 364: 1595-1606.

76 Taveira-Dasilva AM, Hathaway O, Stylianou M, et al. Changes in lung function and chylous effusions in patients with lymphangioleiomyomatosis treated with sirolimus. Ann Intern Med 2011; 154: 797-805.

77 Bissler JJ, McCormack FX, Young LR, et al. Sirolimus for angiomyolipoma in tuberous sclerosis complex or lymphangioleiomyomatosis. N Engl J Med 2008; 358: 140-151.

78 Johnson SR, Cordier JF, Lazor R, et al. European Respiratory Society guidelines for the diagnosis and management of lymphangioleiomyomatosis. Eur Respir J 2010; 35: 14-26.

79 Almoosa KF, Ryu JH, Mendez J, et al. Management of pneumothorax in lymphangioleiomyomatosis: effects on recurrence and lung transplantation complications. Chest 2006; 129: $1274-1281$. 
80 Raghu G, Weycker D, Edelsberg J, et al. Incidence and prevalence of idiopathic pulmonary fibrosis. Am J Respir Crit Care Med 2006; 174: 810-816.

81 Costabel U. Emerging potential treatments: new hope for idiopathic pulmonary fibrosis patients? Eur Respir Rev 2011; 20 : 201-207.

82 El-Chemaly S, Ziegler SG, Calado RT, et al. Natural history of pulmonary fibrosis in two subjects with the same telomerase mutation. Chest 2011; 139: 1203-1209.

83 Demedts M, Behr J, Buhl R, et al. High-dose acetylcysteine in idiopathic pulmonary fibrosis. N Engl J Med 2005; 353: 2229-2242.

84 Raghu G, Anstrom KJ, King TE Jr, et al. Prednisone, azathioprine, and N-acetylcysteine for pulmonary fibrosis. N Engl J Med 2012; 366: 1968-1977.

85 Azuma A, Nukiwa T, Tsuboi E, et al. Double-blind, placebo-controlled trial of pirfenidone in patients with idiopathic pulmonary fibrosis. Am J Respir Crit Care Med 2005; 171: 1040-1047.

86 Noble PW, Albera C, Bradford WZ, et al. Pirfenidone in patients with idiopathic pulmonary fibrosis (CAPACITY): two randomised trials. Lancet 2011; 377: 1760-1769.

87 Richeldi L, Costabel U, Selman M, et al. Efficacy of a tyrosine kinase inhibitor in idiopathic pulmonary fibrosis. $N$ Engl J Med 2011; 365: 1079-1087.

88 Walter N, Collard HR, King TE Jr. Current perspectives on the treatment of idiopathic pulmonary fibrosis. Proc Am Thorac Soc 2006; 3: 330-338.

89 Selman M, Pardo A. Role of epithelial cells in idiopathic pulmonary fibrosis: from innocent targets to serial killers. Proc Am Thorac Soc 2006; 3: 364-372.

90 Alder JK, Chen JJ, Lancaster L, et al. Short telomeres are a risk factor for idiopathic pulmonary fibrosis. Proc Natl Acad Sci USA 2008; 105: 13051-13056.

91 Rosas IO, Ren P, Avila NA, et al. Early interstitial lung disease in familial pulmonary fibrosis. Am J Respir Crit Care Med 2007; 176: 698-705.

92 Seibold MA, Wise AL, Speer MC, et al. A common MUC5B promoter polymorphism and pulmonary fibrosis. $N$ Engl J Med 2011; 364: 1503-1512.

93 Ebina M, Shimizukawa M, Shibata N, et al. Heterogeneous increase in CD34-positive alveolar capillaries in idiopathic pulmonary fibrosis. Am J Respir Crit Care Med 2004; 169: 1203-1208.

94 Cosgrove GP, Brown KK, Schiemann WP, et al. Pigment epithelium-derived factor in idiopathic pulmonary fibrosis: a role in aberrant angiogenesis. Am J Respir Crit Care Med 2004; 170: 242-251.

95 Burdick MD, Murray LA, Keane MP, et al. CXCL11 attenuates bleomycin-induced pulmonary fibrosis via inhibition of vascular remodeling. Am J Respir Crit Care Med 2005; 171: 261-268.

96 Stockmann C, Kerdiles Y, Nomaksteinsky M, et al. Loss of myeloid cell-derived vascular endothelial growth factor accelerates fibrosis. Proc Natl Acad Sci USA 2010; 107: 4329-4334.

97 Cursiefen C, Maruyama K, Jackson DG, et al. Time course of angiogenesis and lymphangiogenesis after brief corneal inflammation. Cornea 2006; 25: 443-447.

98 Yamashita M, Iwama N, Date F, et al. Characterization of lymphangiogenesis in various stages of idiopathic diffuse alveolar damage. Hum Pathol 2009; 40: 542-551.

99 Makinen T, Jussila L, Veikkola T, et al. Inhibition of lymphangiogenesis with resulting lymphedema in transgenic mice expressing soluble VEGF receptor-3. Nat Med 2001; 7: 199-205.

100 Hainis KD, Sznajder JI, Schraufnagel DE. Lung lymphatics cast from the airspace. Am J Physiol 1994; 267: L199-L205.

101 Marchetti C, Poggi P, Clement MG, et al. Lymphatic capillaries of the pig lung: TEM and SEM observations. Anat Rec 1994; 238: 368-373.
102 Peao MN, Aguas AP, de Sá CM, et al. Scanning electron microscopy of the deep lymphatic network of the murine lung as viewed in corrosion casts. Lymphology 1993; 26: 42-48.

103 Leak LV. Lymphatic removal of fluids and particles in the mammalian lung. Environ Health Perspect 1980; 35: 55-76.

104 Ebina M, Shibata N, Ohta $\mathrm{H}$, et al. The disappearance of subpleural and interlobular lymphatics in idiopathic pulmonary fibrosis. Lymphat Res Biol 2010; 8: 199-207.

105 Kambouchner M, Bernaudin JF. Intralobular pulmonary lymphatic distribution in normal human lung using D2-40 antipodoplanin immunostaining. J Histochem Cytochem 2009; 57: 643-648.

106 El-Chemaly S, Malide D, Zudaire E, et al. Abnormal lymphangiogenesis in idiopathic pulmonary fibrosis with insights into cellular and molecular mechanisms. Proc Natl Acad Sci USA 2009; 106: 3958-3963.

107 Koyama S, Sato E, Haniuda M, et al. Decreased level of vascular endothelial growth factor in bronchoalveolar lavage fluid of normal smokers and patients with pulmonary fibrosis. Am Respir Crit Care Med 2002; 166: 382-385.

108 Meyer KC, Cardoni A, Xiang ZZ. Vascular endothelial growth factor in bronchoalveolar lavage from normal subjects and patients with diffuse parenchymal lung disease. J Lab Clin Med 2000; 35: 332-338.

109 Chang LK, Garcia-Cardena G, Farnebo F, et al. Dose-dependent response of FGF-2 for lymphangiogenesis. Proc Natl Acad Sci USA 2004; 101: 11658-11663.

110 Saunders WB, Bohnsack BL, Faske JB, et al. Coregulation of vascular tube stabilization by endothelial cell TIMP-2 and pericyte TIMP-3. J Cell Biol 2006; 175: 179-191.

111 Sakai T, Satoh K, Matsushima K, et al. Hepatocyte growth factor in bronchoalveolar lavage fluids and cells in patients with inflammatory chest diseases of the lower respiratory tract: detection by RIA and in situ hybridization. Am J Respir Cell Mol Biol 1997; 16: 388-397.

112 Antoniades HN, Neville-Golden J, Galanopoulos T, et al. Expression of monocyte chemoattractant protein $1 \mathrm{mRNA}$ in human idiopathic pulmonary fibrosis. Proc Natl Acad Sci USA 1992; 89: 5371-5375.

113 Car BD, Meloni F, Luisetti M, et al. Elevated IL-8 and MCP-1 in the bronchoalveolar lavage fluid of patients with idiopathic pulmonary fibrosis and pulmonary sarcoidosis. Am J Respir Crit Care Med 1994; 149: 655-659.

114 Kajiya K, Hirakawa S, Ma B, et al. Hepatocyte growth factor promotes lymphatic vessel formation and function. EMBO J 2005; 24: 2885-2895.

115 Bjermer L, Lundgren R, Hallgren R. Hyaluronan and type III procollagen peptide concentrations in bronchoalveolar lavage fluid in idiopathic pulmonary fibrosis. Thorax 1989; 44: 126-131.

116 Jiang D, Liang J, Fan J, et al. Regulation of lung injury and repair by Toll-like receptors and hyaluronan. Nat Med 2005; 11: 1173-1179.

$117 \mathrm{Li} \mathrm{Y,} \mathrm{Jiang} \mathrm{D,} \mathrm{Liang} \mathrm{J,} \mathrm{et} \mathrm{al.} \mathrm{Severe} \mathrm{lung} \mathrm{fibrosis} \mathrm{requires} \mathrm{an}$ invasive fibroblast phenotype regulated by hyaluronan and CD44. J Exp Med 2011; 208: 1459-1471.

118 Garantziotis S, Zudaire E, Trempus CS, et al. Serum inter-alphatrypsin inhibitor and matrix hyaluronan promote angiogenesis in fibrotic lung injury. Am I Respir Crit Care Med 2008; 178: 939-947.

119 Guo LX, Zou K, Ju JH, et al. Hyaluronan promotes tumor lymphangiogenesis and intralymphantic tumor growth in xenografts. Acta Biochim Biophys Sin (Shanghai) 2005; 37: 601-606.

120 Itano N, Zhuo L, Kimata K. Impact of the hyaluronan-rich tumor microenvironment on cancer initiation and progression. Cancer Sci 2008; 99: 1720-1725.

121 Nedvetzki S, Gonen E, Assayag N, et al. RHAMM, a receptor for hyaluronan-mediated motility, compensates for CD44 in inflamed CD44-knockout mice: a different interpretation of redundancy. Proc Natl Acad Sci USA 2004; 101: 18081-18086. 
122 Salven P, Mustjoki S, Alitalo R, et al. VEGFR-3 and CD133 identify a population of CD34+ lymphatic/vascular endothelial precursor cells. Blood 2003; 101: 168-172.

123 Religa P, Cao R, Bjorndahl M, et al. Presence of bone marrowderived circulating progenitor endothelial cells in the newly formed lymphatic vessels. Blood 2005; 106: 4184-4190.

124 Maruyama K, Ii M, Cursiefen C, et al. Inflammation-induced lymphangiogenesis in the cornea arises from CD11b-positive macrophages. J Clin Invest 2005; 115: 2363-2372.

125 Kerjaschki D, Huttary N, Raab I, et al. Lymphatic endothelial progenitor cells contribute to de novo lymphangiogenesis in human renal transplants. Nat Med 2006; 12: 230-234.

126 Jeon BH, Jang C, Han J, et al. Profound but dysfunctional lymphangiogenesis via vascular endothelial growth factor ligands from $\mathrm{CD} 11 \mathrm{~b}+$ macrophages in advanced ovarian cancer. Cancer Res 2008; 68: 1100-1109.

127 Kataru RP, Jung K, Jang C, et al. Critical role of CD11b+ macrophages and VEGF in inflammatory lymphangiogenesis, antigen clearance, and inflammation resolution. Blood 2009; 113: 5650-5659.

128 Kim KE, Koh YJ, Jeon BH, et al. Role of CD11b+ macrophages in intraperitoneal lipopolysaccharide-induced aberrant lymphangiogenesis and lymphatic function in the diaphragm. Am J Pathol 2009; 175: 1733-1745.
129 Lee JY, Park C, Cho YP, et al. Podoplanin-expressing cells derived from bone marrow play a crucial role in postnatal lymphatic neovascularization. Circulation 2010; 122: 1413-1425.

130 Karpanen T, Alitalo K. Molecular biology and pathology of lymphangiogenesis. Annu Rev Pathol 2008; 3: 367-397.

131 Schaberg T, Rau M, Stephan H, et al. Increased number of alveolar macrophages expressing surface molecules of the CD11/CD18 family in sarcoidosis and idiopathic pulmonary fibrosis is related to the production of superoxide anions by these cells. Am Rev Respir Dis 1993; 147: 1507-1513.

132 El-Chemaly S, Pacheco-Rodriguez G, Ikeda Y, et al. Lymphatics in idiopathic pulmonary fibrosis: new insights into an old disease. Lymphat Res Biol 2009; 7: 197-203.

133 Marchal-Somme J, Uzunhan Y, Marchand-Adam S, et al. Cutting edge: nonproliferating mature immune cells form a novel type of organized lymphoid structure in idiopathic pulmonary fibrosis. J Immunol 2006; 176: 5735-5739.

134 Pierce EM, Carpenter K, Jakubzick C, et al. Idiopathic pulmonary fibrosis fibroblasts migrate and proliferate to CC chemokine ligand 21. Eur Respir J 2007; 29: 1082-1093.

135 Oka M, Iwata C, Suzuki HI, et al. Inhibition of endogenous TGFbeta signaling enhances lymphangiogenesis. Blood 2008; 111: 4571-4579. 